\title{
Lame cows on Australian dairy farms: A comparison of farmer-identified lameness and formal lameness scoring, and the position of lame cows within the milking order
}

\author{
D. S. Beggs, ${ }^{*}$ E. C. Jongman, P. H. Hemsworth, and A. D. Fisher \\ Animal Welfare Science Centre, Faculty of Veterinary and Agricultural Sciences, University of Melbourne, Australia, 3010
}

\section{ABSTRACT}

On Australian pasture-based farms, where cows may often walk several kilometers and stand for several hours per day in a crowded concrete yard while they wait to be milked, the potential for lameness to negatively affect animal welfare is of ongoing concern. Several studies have shown that farmers tend to underestimate the incidence of lameness. Further, improving farmer diagnosis/identification of lameness is likely to result in more prompt treatment, which in turn will improve clinical and animal welfare outcomes. We scored 19,154 cows over 50 farms for lameness, in herd groups ranging from approximately 100 to 1,000 cows, as they left the milking parlor. We compared these results with farmerdiagnosed lameness records on the same day. We used a scoring system of 0 , walks normally; 1 , walks unevenly; 2 , lame; and 3, very lame. All very lame cows had been detected by the farmer, but overall, farmers detected only $24 \%$ of cows identified by lameness scoring. An analysis of the position of lame cows within the milking order showed that lameness scoring of the entire herd was necessary to detect all the lame cows as only $60 \%$ of lame cows appeared in the last $30 \%$ of cows to be milked. However, lameness scoring only the last 200 cows to be milked could be used as a screening test to identify herds with a lameness prevalence below a given threshold.

Key words: dairy cow, lameness prevalence, lameness scoring

\section{INTRODUCTION}

Lameness remains a common problem of dairy cattle worldwide. As well as being a significant animal welfare concern (von Keyserlingk et al., 2009; Fisher and Webster, 2013; Hemsworth et al., 2015), lame cows

Received March 30, 2018.

Accepted October 20, 2018

*Corresponding author: dbeggs@unimelb.edu.au have reduced fertility, milk production, and BW, as well as incurring treatment costs and being at risk of premature culling (Green et al., 2002; Bruijnis et al., 2012; Grant, 2012; Fabian et al., 2014). On Australian pasture-based farms, where cows may often walk several kilometers per day and stand for several hours per day in a crowded concrete yard while they wait to be milked (Beggs et al., 2015), the potential for lameness to negatively affect animal welfare is of ongoing concern.

Several studies have shown that when farmers do not use systematic lameness scoring systems, they tend to underestimate the incidence of lameness in their herds (Espejo et al., 2006; Š́rová et al., 2011; Leach et al., 2013; Fabian et al., 2014). Improving farmer diagnosis/ identification of lameness is likely to result in more prompt treatment (Alawneh et al., 2012), which in turn will likely improve clinical outcomes (Leach et al., 2012) and thus also improve animal welfare outcomes.

To that end, both the Australian and New Zealand dairy industries have developed extension programs (known respectively as "Healthy Hooves" and "Healthy Hoof") promoting the formal lameness scoring of dairy herds on a regular basis (Dairy Australia, 2015; DairyNZ, 2017). Both extension programs use a 0 to 3 scale similar to that described by Barker et al. (2010), adapted slightly to suit local conditions and language use. Video instructions and print material resources are available that show farmers how to score lameness in a consistent way as cows leave the milking parlor. The uptake of lameness scoring in Australia remains low because, anecdotally at least, farmers appear to believe that they are skilled at identifying clinically lame cows, the time/effort required, and because lameness scoring is seen as a low priority at times of year when it is not a major clinical problem (Dairy Australia, 2016). Farm size may also be a barrier to farmers participating in lameness scoring.

Large herds of more than 500 cows with long milking durations of 3 to $5 \mathrm{~h}$ are increasingly common in Australia, which means lameness scoring entire herds can require significant effort and resources (Beggs et 
al., 2015; Dairy Australia, 2017). For welfare auditing purposes, or identifying farms likely to benefit from assistance with their lameness management, it may be useful if herd lameness prevalence could be estimated by lameness scoring a subsample of the entire herd. In the Australian context, where cows walk several kilometers per day to and from the paddock, it seems logical that lame cows might walk more slowly or be slower to leave the paddock, and thus be concentrated toward the end of the milking order. The extent to which this happens has not been previously reported but is worthy of examination. For example, if it were possible to identify most lame cows by lameness scoring only the last half of cows milked it could result in a significant saving of resources.

We scored 50 herds for lameness in the order cows left the milking parlor. We (1) compared the results with farmer-recorded lameness to test the hypothesis that Australian dairy farmers underestimate the prevalence of lameness in their herds, and (2) examined the extent to which lame cows were concentrated toward the back of the milking order to assess whether lameness scoring a subset of cows might be useful for identifying the majority of lame cows or estimating herd lameness prevalence.

\section{MATERIALS AND METHODS}

Fifty seasonal or split-calving dairy farms were selected on the basis of convenience from the client base (approximately 300 dairy farms) of a large veterinary practice in western Victoria, the highest producing dairy region in Australia. The sample of farms was chosen to be broadly representative of dairy farms in the area, selected to ensure a range of farm sizes. Observations were conducted over a 14-mo period at times based on convenience for the researcher. We made a positive attempt to time visits during mid to late lactation for the majority of cows, because this would maximize the proportion of the herd that was lactating at the time of the visit. All lameness score observations were carried out by the first author, a senior lecturer in cattle medicine at the University of Melbourne, also a veterinary practitioner with more than $20 \mathrm{yr}$ of experience diagnosing and treating lame cows, who had familiarity and experience with the Healthy Hooves resources.

Before milking, the farmers provided the identities of and cows in the herd that (1) were currently under treatment for lameness, or (2) were separated into a second herd that walks a lesser distance because they were lame. All cows were then scored for lameness at a single milking in the order that cows left the milking parlor using the 0 to 3 scale promoted by Dairy Australia, described in Table 1. Under this system, cows with scores 0 are not lame, cows with a score of 1 are described as walking unevenly but not requiring urgent treatment. Cows with a score of 2 or 3 are considered to be lame. Cows that could not be scored for lameness (for example, because they were walking too closely together or running) were recorded as lameness score $\mathrm{X}$. Such cows were excluded from the analysis of prevalence, but included for the purpose of calculating the cut-off points for the last 10, 20, and $30 \%$ of the milking order. Due to the rate of cows exiting the milking parlor, individual cows were not identified unless they were very lame (score 3), in which case their visual identification numbers were recorded and reported to the farmer, to ensure these cows were identified for treatment.

It is common practice on Australian dairy farms to milk sick and lame cows in a separate "hospital herd," which walks a smaller distance. Also, as cow numbers increase, it is common for Australian farmers to milk cows as 2 to 3 sub-groups, which are kept in paddocks separate from one another and milked separately. Where groups of cows were milked separately, all cows were included in prevalence calculations, but only the largest group was included in the milking order analysis.

Lameness scores were entered into a spreadsheet where initial calculations were made at the farm level, and then entered into SPSS (V25, IBM Corp., Armonk, NY) for further analysis. The farmer-diagnosed prevalence of lame cows was calculated as the percentage of milking cows that the farmer had identified as lame before the milking at which observations were taken. The prevalence of lame cows was calculated as the percentage of all cows milked that had a lameness score of 2 or 3.

For each herd, we calculated the proportion of lame cows in the last 10,20 , and $30 \%$ of the milking order, to determine whether the majority of lame cows could be successfully identified without the need to lameness score the entire herd.

Linear regression using lameness prevalence as the outcome variable and lameness prevalence of the last 100 or 200 cows and the last $30 \%$ of cows (with a minimum of 200 cows) as the predictor was used to examine whether the these could be used to predict the overall lameness prevalence. Where the group size was less than the threshold, all cows in the group were included.

The study was conducted with animal ethics approval from the University of Melbourne Faculty of Veterinary and Agricultural Sciences Animal Ethics Committee.

\section{RESULTS}

A total of 19,154 cows on 50 farms were scored for lameness by the same experienced observer. This rep- 
Table 1. Instructions for lameness scoring of dairy cattle provided in the Australian Dairy Industry "Health Hooves" extension program

\begin{tabular}{|c|c|c|c|c|c|}
\hline Lameness score & Walking speed & Stride & Weight bearing & Backline & Head \\
\hline
\end{tabular}

1: Walks unevenly. Minor action required. Record and keep an eye on her; some cows normally walk unevenly.

\section{2: Lame. Action} required. This cow needs to be reported, drafted, and examined within $24 \mathrm{~h}$.

3: Very lame. Urgent action required. Draft and examine as soon as possible within $24 \mathrm{~h}$. May require a veterinarian.
Not normally affected, should easily maintain position in the herd.

\section{May be slower than} normal; may stop, especially when turning a corner.

Very slow, stops often, and will lie down in paddock. Cannot keep up with the healthy herd.

\begin{abstract}
May have uneven stride, rhythm, or both. Rear foot placement may miss front foot placement.
\end{abstract}

Shortened strides rear foot placement falls short of front foot placement.

Shortened and very uneven. Non-lame leg will swing through quickly.
May stand or walk unevenly but difficult to identify which leg(s) are affected.

\section{Uneven-lame leg} can be identified.

Lame leg easy to identify; limping; may barely stand on lame leg(s).
Straight when standing, may be mildly arched when walking.

May have slight bob and or may be held lower than normal.

Often arched when standing and walking.

Bobs up and down when walking.

Arched when standing and walking.

Large head movements up and down when walking.

${ }^{1}$ Dairy Australia (2015).

resented approximately $15 \%$ of the client base of veterinary clinic from which the study was conducted, and we estimated that it represented approximately $4 \%$ of farms and $7 \%$ of cows within the local western-Victorian dairying region of Australia. There was a range of herd sizes with 16 small ( $<300$ cows), 13 medium (300-499), 11 large (500-749), and 10 very large (750-1,087) herds. The distribution of herd sizes can be seen in Figure 1. Most farms (32/50) had a seasonal calving pattern, with 17 of the remaining farms having a split calving pattern (2 discreet calving periods during the year) and one farm having a year-round calving pattern. There were 25 rotary dairy and 25 herringbone dairy sheds. Visits were conducted between 64 and $310 \mathrm{~d}$ from the beginning of the most-recent calving period in all herds except the year-round calving herd and 2 of the split calving herds. The majority of visits $(35 / 50)$ took place during the drier months of November-February, and no visits took place between April and June when most farms in the local area were calving. Less than $1 \%$ of cows on any farm were excluded from the analysis because they were unable to be scored for lameness.

\section{Farmer Estimates of Lameness Prevalence}

The mean farm prevalence of lame cows (score 2 or 3 ) based on lameness scoring ranged from 0 to $11.4 \%$ (mean $3.8 \%$ ), with $4.2 \%$ of cows overall being lame. These results contrast with the farmer estimates of lameness prevalence. On individual farms, the farmerdiagnosed prevalence of lameness was between 0 and $3.6 \%$ (mean $0.82 \%$ ). On average, farmers had diagnosed approximately $24 \%$ of cows identified by lameness scoring but there was wide variation between farms (range 0-100\%, interquartile range $4-31 \%$ ). All the very lame (score 3) cows had been identified by the farmer and were either marked for treatment or in a separately milked hospital herd. There was no evidence of a relationship between herd size and lameness prevalence (Figure 1). Having a hospital herd that walked a lesser

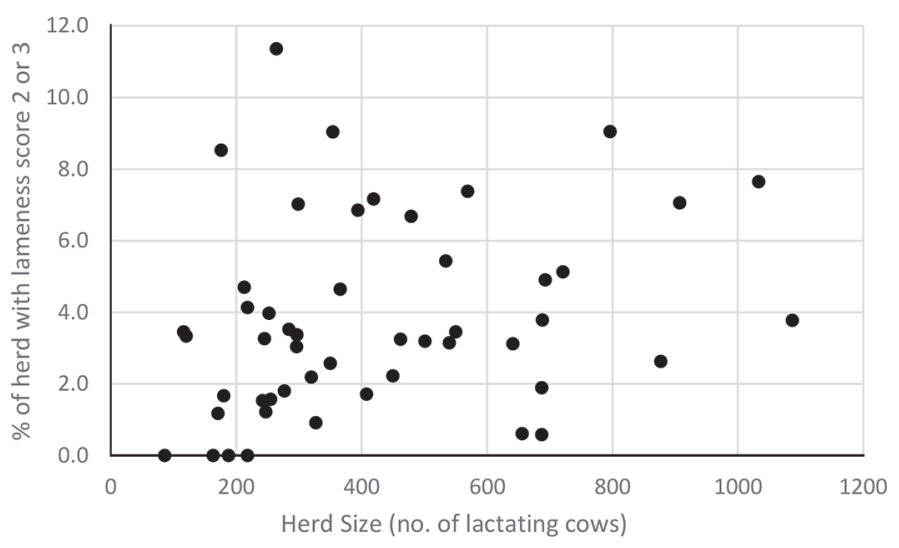

Figure 1. The relationship between herd size and lameness prevalence scoring for 50 herds scored for lameness during mid to late lactation $\left(\mathrm{R}^{2}=0.07\right)$. 
distance was more common as herd size increased $(100 \%$ of very large herds, $89 \%$ of large herds, $77 \%$ of medium herds, and $69 \%$ of small herds), but it was not related to lameness prevalence or the proportion of lame cows identified by the farmer.

\section{Position of Lame Cows in the Milking Order}

The distribution of group sizes was slightly different for milking order calculations because only the largest group was considered on each farm. Cows were milked in separate groups (aside from hospital herds) on 5 farms, all of which milked more than 680 cows in total. There were 5 groups of $>750$ cows, 12 groups of 500 to 749 cows, 11 groups of 300 to 499 cows, 14 groups of 200 to 299 cows, 7 herds with 100 to 199 cows, and 1 herd with 86 cows. Of the smaller farms, all but 2 had a separate hospital herd. One of the smaller farms with no hospital herd also had no lame cows.

Lame cows appeared disproportionately toward the back of the herd with 26\% (SD 2.4\%), $47 \%$ (SD 2.7\%), and $62 \%$ (SD 2.3\%) of lame cows appearing in the last 10,20 , and $30 \%$ of the milking order respectively. Table 2 and Figures 2, 3, and 4 show linear regression analysis estimating prevalence of lameness in a herd of cows based on the last 100 cows, last 200 cows, or last $30 \%$ or 200 cows (whichever is the greater). When 100 cows were scored, the lameness prevalence was underestimated in one herd by $2.2 \%$, and in the other 49 it was overestimated between 0 and $11.4 \%$. When 200 cows were scored, and also when the greater of 200 cows or $30 \%$ of the herd were scored, the lameness prevalence was underestimated in one herd by $0.2 \%$, and in the other 49 it was overestimated between 0 and $5.5 \%$.

\section{DISCUSSION}

The incidence of lameness varies with the time of year and stage of lactation in Australia, being more of a problem in the wetter months and during early lacta- tion (Ranjbar, 2017). However, lameness has potential to be an important animal welfare issue through the entire year; at times when a lower percentage of the herd is lame, there is potentially a higher percentage of cows lactating. Rather than timing our visit to coincide with the expected peak of lameness, we aimed instead to visit when the maximum number of cows were milking and there is not necessarily a management focus on lameness. For most seasonal calving herds, most cows are in mid to late lactation at this time. From an animal welfare perspective, our study directly compared the proportion of cows that were receiving some sort of attention for their lameness with those that should have been receiving such attention on a given day.

Our mean farm lameness prevalence of $3.8 \%$ was considerably lower than previous studies. For example, a New Zealand study (Fabian et al., 2014) reported 8.3\% of cows were lame, but these farms were visited at the time of the expected highest lameness incidence and it seems reasonable that the prevalence of lameness might be more than twice as high when it is at its maximum. A recent Australian study, where $18.9 \%$ (range 5 to $44.5 \%$ ) of cows were lame, included visits throughout a 12 -mo period and would have included farms at their time of maximum lameness (Ranjbar et al., 2016). Thus, these studies are not directly comparable with our data.

\section{Researcher-Identified Lameness}

The scoring system used in this study, similar to the Agriculture and Horticulture Development Board dairy mobility score widely used in the United Kingdom (AHDB, 2015), was designed as a practical on-farm tool and is promoted by industry in Australia and New Zealand for use by farmers, with little more than posters and videos as initial training, and a general recommendation that lame cows should be examined as soon as practicable and very lame cows should be examined urgently (Dairy Australia, 2015; DairyNZ, 2017). No

Table 2. Linear regression analysis comparing the predictive value of estimating whole herd lameness in 50 herds based on either lameness scoring the last 100 or last 200 cows to be milked (or all cows if fewer cows than this)

\begin{tabular}{lccc}
\hline Item & Last 100 cows $^{1}$ & Last 200 cows $^{2}$ & $\begin{array}{c}\text { Last } 200 \text { cows or } 30 \% \\
\text { of cows milked (if greater) }\end{array}$ \\
\hline $\mathrm{R}^{2}$ & 0.77 & 0.84 & 0.85 \\
Constant & 0.55 & 0.36 & 0.36 \\
$\mathrm{~B}$ (coefficient) & 0.38 & 0.58 & 0.59 \\
$\mathrm{SE}$ & 0.03 & 0.04 & 0.04 \\
$95 \%$ CI for B & $0.32-0.44$ & $0.51-0.65$ & $0.51-0.66$ \\
\hline
\end{tabular}

${ }^{1}$ Including 1 herd with fewer than 100 cows.

${ }^{2}$ Including 8 herds with fewer than 200 cows. 


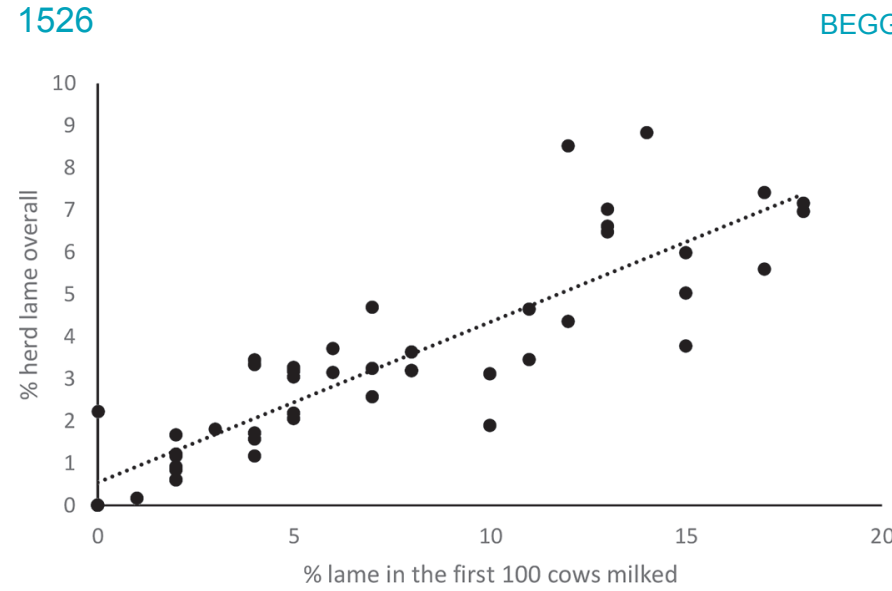

Figure 2. The relationship between the proportion of the herd lame overall and the proportion of lame cows in the last 100 cows milked $\left(\mathrm{R}^{2}=0.77\right)$.

reports are available, to our knowledge, regarding the effectiveness of this training, but the lameness scoring system has been shown to be robust in terms of interand intra-observer agreement in several studies where researchers used each other for calibration (Barker et al., 2010; Main et al., 2010; Fabian et al., 2014). It must be recognized that the results of this study are only true within the limits of the observer's reliability and repeatability, which is difficult to quantify. However, we consider that the results and conclusions remain valid because, from an animal welfare perspective, cows identified as lame by an experienced dairy cattle veterinarian should be examined and treated. If the researcher was in fact underestimating true lameness prevalence, this makes the conclusions of our study more conservative.

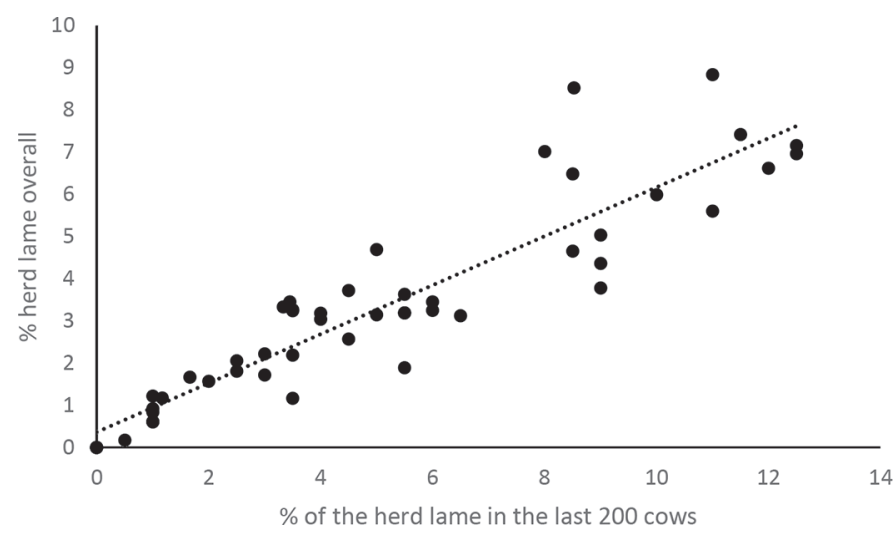

Figure 3. The relationship between the proportion of the herd lame overall and the proportion of lame cows in the last 200 cows milked (or all cows if fewer than 200 cows in the herd; $\mathrm{R}^{2}=0.84$ ).

\section{Farmer-Identified Lameness}

Our results in terms of the proportion of lame cows identified by the farmer are broadly similar to other studies, including the studies with higher overall lameness prevalence described above. Fabian et al. (2014) in New Zealand pasture-based dairy herds reported that only $27.3 \%$ (range $0-95 \%$ ) of cows with reduced mobility had been identified as such by farmers and Ranjbar et al. (2016) reported that the prevalence of lameness estimated by farmers was only $27 \%$ of that identified by lameness scoring. Results have been similar in housed cows. In the United Kingdom, Whay et al. (2003) reported farmers estimating the prevalence of lameness to be $23 \%$ of the actual prevalence, and in a study by Leach et al. (2010), the mean estimate of lameness by farmers was $7.9 \%$ compared with $36 \%$ identified by lameness scoring. Espejo et al. (2006) reported the mean prevalence of detected lameness to be $32 \%$ of actual lameness by farmers in freestall barns in Minnesota. Sárová et al. (2011) found that in 14 Czech loose-housed dairy farms, farmers estimated lameness prevalence to be between 0 and $20 \%$, whereas lameness scoring identified 9 to $64 \%$ of the herds as lame and there was no correlation between farmer estimate and prevalence estimated by lameness scoring. While the absolute lameness prevalence was not particularly high in our study herds, small percentages of lame cows can still amount to significant adverse animal welfare outcomes, especially in larger herds when a significant number of lame cows may remained undiagnosed and untreated. Our results highlight the potential animal welfare benefits of formal and systematic lameness scoring of dairy herds for improving identification and

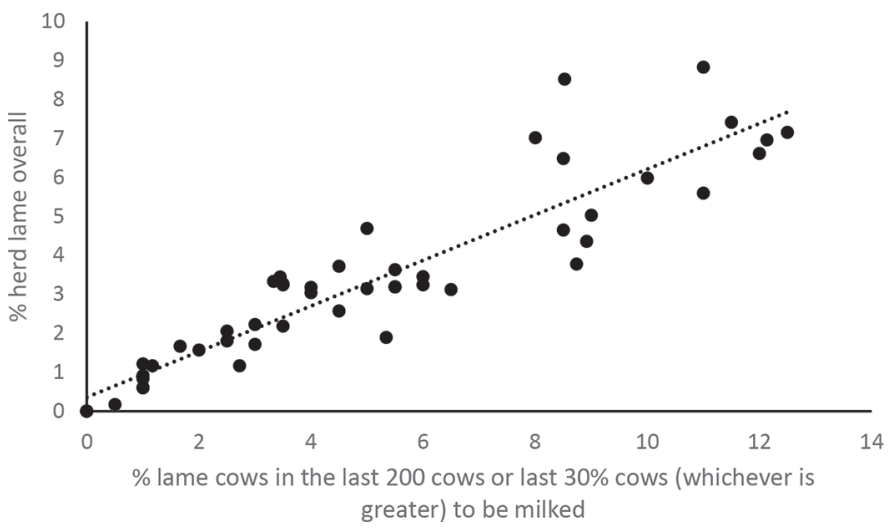

Figure 4. The relationship between the percent of lame cows in the last 200 cows or $30 \%$ of the herd (whichever is greater) to be milked and the percent of lame cows overall. $\mathrm{R}^{2}=0.85$. 
treatment of lame cows, even at times of the year when farmer perception is that lameness prevalence is low.

\section{Position of Lame Cows in the Milking Order}

We concluded that lameness scoring only cows which are milked later in the milking order would not be very useful for identifying all lame cows in a herd for the purposes of treatment as only $60 \%$ of lame cows were found in the last $30 \%$ of cows to be milked, leaving $40 \%$ of the lame cows undiagnosed. As our study was undertaken on a single day, it is worth considering whether the results would likely be repeatable on a given farm. Previous studies have demonstrated a consistency to the milking order, even in large herds (Botheras, 2006; Berry and McCarthy, 2012). A study of large Australian herds pasture-based herds showed that, although cows in the first and last $20 \%$ of the milking order maintained their position much more consistently than cows in the middle, milking order position of cows was highly correlated within a day and between one month and the next, suggesting that cows are motivated to maintain their preferred milking order position (Beggs et al., 2018). Thus, it is probable, even though not demonstrated in our study, that our results would be repeatable within an individual farm.

It is interesting to speculate as to why lame cows would be distributed toward the end of the milking order. One potential explanation is that lame cows walk more slowly or leave the paddock more slowly, and indeed it seems likely that very lame cows (which by definition walk more slowly than the rest of the herd) would filter toward the back of the herd as cows walk to the dairy. In a study of 10 New Zealand herds, the authors examined the position of cows in the walking order and the milking order both before and after they became lame. They showed fair agreement between the walking order (the order cows walked to the dairy) and the milking order. Cows later in both the walking order and the milking order were more likely to become lame (odds ratio $=2.8$ and 2.0, respectively; Sauter-Louis et al., 2004). The authors theorized that the rear group might have been more vulnerable to becoming lame because they were the cows most likely to be affected by an impatient farmer hurrying cows along a track, hurrying them out of the milking yard, or because they were compacted by a backing gate in the dairy yard. Cows being hurried are forced into tighter groups and make more unplanned foot placements. Thus, they have a greater risk of foot damage from the track or yard surface material. Further work would be required to investigate whether a higher proportion of lame cows toward the end of the milking order could be used as an index to assess the extent to which cows are being hurried as they walk along the track.

A potential limitation of our study was that most herds $(80 \%)$ milked identified lame cows in a separate "sick herd" group that was milked last and did not have to walk as far, and in these herds the identified lame cows were necessarily excluded from milking order calculations. This might induce a bias into the milking order calculations, but as farmer-identified lameness prevalence was generally low $(<3.6 \%)$ we did not consider this likely to be of major significance, and it makes the study potentially more representative of herds that do milk identified lame cows in separate herds.

As with other welfare measures, lameness assessments may be conducted for a variety of reasons. Apart from the identification and treatment of lame cows, the prevalence of lameness in a herd might be used as part of a certification tool that enables farmers to be members of assurance schemes, to make specific welfare claims, for monitoring the effect of management changes or for benchmarking farms against others (Main et al., 2003; Sørensen and Fraser, 2010). Some have advocated a reduction in sample size as a mechanism for reducing costs (Sørensen et al., 2007; Main et al., 2010). In an Australian context, the most likely use the authors see for such a test would be in animal welfare audits, where having a test that minimizes resources but gives some confidence that the overall prevalence of lameness was below a threshold would be useful. Although in a different farming system using housed cows in the United Kingdom, a previous study demonstrated a similar concept showing that lameness scoring 100 cows in the middle of the herd order produced an estimate of prevalence within $5 \%$ of the true prevalence on $83 \%$ of farms (Main et al., 2010). The study also concluded that by observing the presence of severely lame cows, especially at the end of milking, farms that are most likely to benefit from assistance with their lameness management could be identified. In most Australian dairies, it is possible to determine how many cows have been milked either from the dairy infrastructure in a rotary dairy, or by counting the number of runs milked in a herringbone dairy. Thus, scoring the last given portion of a herd to be milked is a practical option. Given the common herd sizes in Australia, we investigated whether lameness scoring the last 100 or 200 cows to be milked, or in case more cows were required the greater of the last 200 or the last $30 \%$ of the herd, would be suitable for this purpose. There was only one low prevalence herd ( $2.2 \%$ lame cows) where lameness scoring a subset of the herd underestimated the prevalence of lameness overall. When 200 cows were scored for lameness, the prevalence of lameness in the 
last 200 cows was within $5.4 \%$ of the overall prevalence. Scoring more cows $(30 \%$ of the herd if this was more than 200 cows) did not materially change the outcome. This result must be viewed with caution because it is affected by the overall low prevalence of lameness in our study. For example, in a herd with an overall prevalence of $5 \%$, the estimate of prevalence based on any subset of 100 cows or more cannot be underestimated by more than $5 \%$. However, our data make it seem likely that lameness scoring at least 200 cows at the end of the milking order would give some confidence that the overall lameness prevalence was not notably higher than the result obtained. This could be useful as a screening test, identifying herds that were likely to have lameness prevalence above a given threshold for further attention. Further work would need to validate the relationship in other herds with higher lameness prevalence.

\section{CONCLUSIONS}

Unreported lameness remains a welfare concern on Australian dairy farms. Farmers underestimated the prevalence of lameness, diagnosing only 20 to $25 \%$ of the cases found by formal lameness scoring of the entire herd. To detect and treat lame cows, lameness scoring of the entire herd is needed, because scoring the last $30 \%$ of the herd would only detect approximately $60 \%$ of cases. Lameness scoring is a simple test that should be encouraged. Lameness scoring the last 200 cows from the largest group of cows milked in Australian pasture-based dairy herds has the potential for use as a screening test to detect herds with a lameness prevalence below a given threshold.

\section{ACKNOWLEDGMENTS}

The authors are grateful to the staff of the Warrnambool Veterinary Clinic (Warrnambool, Victoria, Australia) and the farmers who graciously allowed us on their farms. We acknowledge the Victorian Department of Economic Development Jobs Transport (Melbourne, Victoria, Australia) and Resources and Dairy Australia Ltd. (Southbank, Victoria, Australia) for their support of this project. This project was also supported through an Australian Government Research Training Program Scholarship.

\section{REFERENCES}

AHDB. 2015. AHDB Dairy Mobility Score. Accessed Oct. 20 2018. https://dairy.ahdb.org.uk/resources-library/technical -information/health-welfare/mobility-score-instructions.
Alawneh, J. I., R. A. Laven, and M. A. Stevenson. 2012. Interval between detection of lameness by locomotion scoring and treatment for lameness: A survival analysis. Vet. J. 193:622-625. https://doi .org/10.1016/j.tvjl.2012.06.042.

Barker, Z. E., K. A. Leach, H. R. Whay, N. J. Bell, and D. C. J. Main. 2010. Assessment of lameness prevalence and associated risk factors in dairy herds in England and Wales. J. Dairy Sci. 93:932-941. https://doi.org/10.3168/jds.2009-2309.

Beggs, D. S., A. D. Fisher, E. C. Jongman, and P. E. Hemsworth 2015. A survey of Australian dairy farmers to investigate animal welfare risks associated with increasing scale of production. J. Dairy Sci. 98:5330-5338. https://doi.org/10.3168/jds.2014-9239.

Beggs, D. S., E. C. Jongman, P. H. Hemsworth, and A. D. Fisher. 2018. Short communication: Milking order consistency of dairy cows in large Australian herds. J. Dairy Sci. 101:603-608. https:// doi.org/10.3168/jds.2017-12748.

Berry, D. P., and J. McCarthy. 2012. Genetic and non-genetic factors associated with milking order in lactating dairy cows. Appl Anim. Behav. Sci. 136:15-19. https://doi.org/10.1016/j.applanim 2011.11.012.

Botheras, N. A. 2006. The behaviour and welfare of grazing dairy cows (Bos taurus): Effects of time away from pasture. PhD Thesis. Faculty of Land and Food Resources, University of Melbourne, Melbourne, Australia.

Bruijnis, M. R. N., B. Beerda, H. Hogeveen, and E. N. Stassen. 2012 Assessing the welfare impact of foot disorders in dairy cattle by a modeling approach. Animal 6:962-970. https://doi.org/10.1017/ S1751731111002606.

Dairy Australia. 2015. Healthy Hooves Investigation Pack Healthy Hooves: Investigation Pack. 1st ed. Dairy Australia Ltd., Southbank, Victoria, Australia.

Dairy Australia. 2016. Dairy welfare, we care animal husbandry survey 2016. Southbank, Victoria, Australia.

Dairy Australia. 2017. Dairy Situation and Outlook June 2017. Dairy Australia Ltd., Southbank, Victoria, Australia.

DairyNZ. 2017. Lameness Field Guide-A Farmer's Guide to Treating Lameness. 2nd ed. DairyNZ Ltd., Hamilton, New Zealand.

Espejo, L. A., M. I. Endres, and J. A. Salfer. 2006. Prevalence of lameness in high-producing Holstein cows housed in freestall barns in Minnesota. J. Dairy Sci. 89:3052-3058. https://doi.org/10.3168/ jds.S0022-0302(06)72579-6.

Fabian, J., R. A. Laven, and H. R. Whay. 2014. The prevalence of lameness on New Zealand dairy farms: A comparison of farmer estimate and locomotion scoring. Vet. J. 201:31-38. https://doi .org/10.1016/j.tvjl.2014.05.011.

Fisher, A. D., and J. R. Webster. 2013. Dairy cow welfare: The role of research and development in addressing increasing scrutiny. Anim. Prod. Sci. 53:924-930. https://doi.org/10.1071/AN12276.

Grant, R. 2012. Economic Benefits of Improved Cow Comfort. Novus International, St. Charles, MO.

Green, L. E., V. J. Hedges, Y. H. Schukken, R. W. Blowey, and A. J. Packington. 2002. The impact of clinical lameness on the milk yield of dairy cows. J. Dairy Sci. 85:2250-2256. https://doi.org/10 .3168/jds.S0022-0302(02)74304-X.

Hemsworth, P. H., D. J. Mellor, G. M. Cronin, and A. J. Tilbrook. 2015. Scientific assessment of animal welfare. N. Z. Vet. J. 63:2430. https://doi.org/10.1080/00480169.2014.966167.

Leach, K. A., E. S. Paul, H. R. Whay, Z. E. Barker, C. M. Maggs, A. K. Sedgwick, and D. C. J. Main. 2013. Reducing lameness in dairy herds - Overcoming some barriers. Res. Vet. Sci. 94:820-825. https://doi.org/10.1016/j.rvsc.2012.10.005.

Leach, K. A., D. A. Tisdall, N. J. Bell, D. C. J. Main, and L. E. Green. 2012. The effects of early treatment for hindlimb lameness in dairy cows on four commercial UK farms. Vet. J. 193:626-632. https:// doi.org/10.1016/j.tvjl.2012.06.043.

Leach, K. A., H. R. Whay, C. M. Maggs, Z. E. Barker, E. S. Paul, A. K. Bell, and D. C. J. Main. 2010. Working towards a reduction in cattle lameness: 1 . Understanding barriers to lameness control on dairy farms. Res. Vet. Sci. 89:311-317. https://doi.org/10.1016/j .rvsc. 2010.02.014 
Main, D. C. J., Z. E. Barker, K. A. Leach, N. J. Bell, H. R. Whay, and W. J. Browne. 2010. Sampling strategies for monitoring lameness in dairy cattle. J. Dairy Sci. 93:1970-1978. https://doi.org/10 .3168/jds.2009-2500.

Main, D. C. J., J. P. Kent, F. Wemelsfelder, E. Ofner, and F. A. M. Tuyttens. 2003. Applications for methods of on-farm welfare assessment. Anim. Welf. 12:523-528.

Ranjbar, S. 2017. Lameness in Pasture-Based Dairy Farms in NSW, Australia. PhD Thesis. Faculty of Veterinary Science, University of Sydney, Sydney, Australia.

Ranjbar, S., A. R. Rabiee, A. Gunn, and J. K. House. 2016. Identifying risk factors associated with lameness in pasture-based dairy herds. J. Dairy Sci. 99:7495-7505. https://doi.org/10.3168/jds .2016-11142.

Šárová, R., I. Stěhulová, P. Kratinová, P. Firla, and M. Špinka. 2011. Farm managers underestimate lameness prevalence in Czech dairy herds. Anim. Welf. 20:201-204.

Sauter-Louis, C. M., R. N. Chesterton, and D. U. Pfeiffer. 2004. Behavioural characteristics of dairy cows with lameness in Taranaki,
New Zealand. N. Z. Vet. J. 52:103-108. https://doi.org/10.1080/ 00480169.2004 .36414 .

Sørensen, J. T., and D. Fraser. 2010. On-farm welfare assessment for regulatory purposes: Issues and possible solutions. Livest. Sci. 131:1-7.

Sørensen, J. T., T. Rousing, S. H. Møller, M. Bonde, and L. Hegelund. 2007. On-farm welfare assessment systems: What are the recording costs? Anim. Welf. 16:237-239.

von Keyserlingk, M. A., J. Rushen, A. M. de Passillé, and D. M. Weary. 2009. Invited review: The welfare of dairy cattle-Key concepts and the role of science. J. Dairy Sci. 92:4101-4111. https:// doi.org/10.3168/jds.2009-2326.

Whay, H. R.. D. C. Main, L. E. Green, and A. J. Webster. 2003. Assessment of the welfare of dairy cattle using animal-based measurements: Direct observations and investigation of farm records. Vet. Rec. 153:197-202. https://doi.org/10.1136/vr.153.7.197. 